\title{
Attentional Modulation of Spatial Integration of Pain: Evidence for Dynamic Spatial Tuning
}

\author{
Alexandre S. Quevedo and Robert C. Coghill \\ Department of Neurobiology and Anatomy, Wake Forest University School of Medicine, Winston-Salem, North Carolina 27157-1010
}

In many sensory modalities, afferent processing is dynamically modulated by attention and this modulation produces altered sensory experiences. Attention is able to alter perceived pain, but the mechanisms involved in this modulation have not been elucidated. To determine whether attention alters spatial integration of nociceptive information, subjects were recruited to evaluate pain from pairs of noxious/innocuous thermal stimuli during different spatial attentional tasks. Divided attention was able to abolish spatial summation and produce inhibition of pain. In contrast, directed attention enhanced pain intensity by partially integrating both stimuli. This dynamic modulation of spatial integration indicates that attention alters spatial dimensions of afferent nociceptive processing to optimize the perceptual response to input from a particular body region or stimulus feature. This dynamic spatial tuning of nociceptive processing provides a new conceptual insight into the functional significance of endogenous pain inhibitory and facilitatory mechanisms.

Key words: pain; psychophysics; attention; plasticity; modulation; receptive field

\section{Introduction}

Spatial summation of sensory information is characterized by the perception of increased intensity when the size of the stimulated area is expanded (Price et al., 1989). This phenomenon provides evidence for spatial integration of afferent information and has been found in different sensory modalities including the visual (Harutiunian-Kozak et al., 2006) and auditory (Buell and Hafter, 1991) systems. Spatial summation in the somatosensory system is a well documented phenomenon (Nielsen and Arendt-Nielsen, 1997) and has been found in a variety of submodalities including innocuous warmth (Hilz et al., 1999), cool (Hilz et al., 1999), and mechanical perception (Greenspan et al., 1997). Extensive spatial summation of pain occurs during noxious thermal (Price et al., 1989; Coghill et al., 1993; Nielsen and Arendt-Nielsen, 1997), electrical (Andersen et al., 1994) and mechanical (Greenspan et al., 1997) stimulation.

Neurons in CNS pathways process information within a localized region of space and a restricted epoch of time. Most studies of acute nociceptive processing have focused mostly on static aspects of receptive field (RF) spatial organization. However, the spatial structure of the receptive field changes as a function of time and can be modulated by cognitive factors such as attention (Compte and Wang, 2006). Task dependent tuning of receptive fields is found across visual (McAdams and Maunsell, 1999), auditory (Ahveninen et al., 2006), and somatosensory (Hayes et al., 1981) systems. Such tuning is associated with altered perceptual experiences as indicated by more frequent and more accurate

Received April 27, 2007; revised Sept. 11, 2007; accepted Sept. 12, 2007

This work was supported by National Institutes of Health Grants R01 NS-39426 and DA 20168. We thank Dr. Morten Hadsel for helpful comments on this manuscript.

Correspondence should be addressed to Robert C. Coghill, Department of Neurobiology and Anatomy, Wake Forest University School of Medicine, Winston-Salem, NC 27157-1010. E-mail: rcoghill@wfubmc.edu. DOI:10.1523/JNEUROSCI.3356-07.2007

Copyright $\odot 2007$ Society for Neuroscience $\quad$ 0270-6474/07/2711635-06\$15.00/0 detection of stimuli (Braun et al., 2002; Quraishi et al., 2006). Attention may be a modulatory factor that produces dynamic alterations of the receptor field sizes of wide dynamic range and nociceptive specific neurons. For example, single-unit electrophysiological recordings indicate that attention can cause the unilateral receptive fields of medullary dorsal horn neurons to expand or shift such that they begin to respond to contralateral noxious stimuli (Hayes et al., 1981). However, the subjectively available perceptual consequences of such receptive field alterations remain unknown.

Indirect evidence suggests that perceived pain intensity during spatial summation can be altered by attention related tasks (Quevedo and Coghill, 2007). Specifically, pain intensity may be amplified by tasks requiring integration of information across large body regions. Pronounced spatial summation would be consistent with nociceptive neurons undergoing receptive field expansion and/or shifts during such tasks. Conversely, pain intensity may be diminished by tasks that require a spatial segregation of attention. Reduced spatial summation would be consistent with task related receptive field reductions. To test the hypothesis that attention can alter the spatial integration of nociceptive information, subjects were recruited to evaluate perceived pain evoked by pairs of noxious stimuli. Different rating tasks were used to manipulate spatial attention.

\section{Materials and Methods}

Subjects. All subjects participating in this study (eight males and seven females) were healthy, pain- and drug-free volunteers between 20 and 39 years old (average age, 26.4). Eleven subjects were white (four females and seven males), one Asian (female), and three black (two females and one male). All subjects gave written, informed consent acknowledging that they would experience experimental painful stimuli, that all methods and procedures were clearly explained, and that they were free to withdraw from the experiment at any time without prejudice. All proce- 


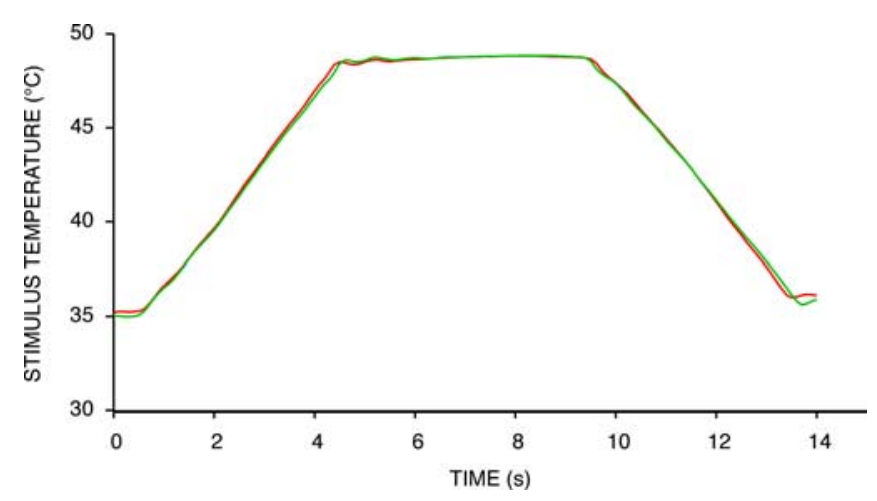

Figure 1. Temporal and quantitative synchronization of stimuli. Stimulus temperatures delivered by each probe were highly similar and were well synchronized (average of 214 paired $49 / 49^{\circ}$ ( trials).

dures were approved by the Institutional Review Board of Wake Forest University School of Medicine.

General stimulation methods. All thermal stimuli were delivered with TSA II devices (Medoc, Ramat Yishai, Israel) using $16 \times 16 \mathrm{~mm}$ stimulus probe(s). All stimuli were at the target temperature for five seconds and used rise and fall rates of $4^{\circ} \mathrm{C} / \mathrm{s}$. Stimuli were delivered to the right or left leg by a single probe or by two probes simultaneously. Paired stimuli were temporally synchronized electronically and monitored on a digital chart recorder (PowerLab/4sp; AD Instruments, Castle, Australia). The stimulus probes were calibrated to insure (quantitatively and temporally) synchronized stimulus delivery for identical (stimulus) temperature (Fig. 1). To further reduce confounds resulting from potentially slight differences in stimulus delivery between probes, the probe positions (proximal/distal) were switched halfway through each experimental session.

A minimum interval of $30 \mathrm{~s}$ between any two consecutive stimuli was maintained throughout the study, and stimuli were sequentially delivered to marked sites in a predetermined spatial order to avoid long-term suppression or sensitization of nociceptive afferents (Price and Dubner, 1977). Stimulus conditions were randomized to avoid order effects. Before and after thermal stimulation, a baseline temperature of $35^{\circ} \mathrm{C}$ was used. All trials using pairs of stimuli had the distance between probes fixed at $10 \mathrm{~cm}$ because, in our previous study, higher inhibition was found at this distance (Quevedo and Coghill, 2007). When paired stimuli were used (i.e., $35 / 49^{\circ} \mathrm{C}$ ), the first temperature reported corresponds to the proximal temperature (i.e., $35^{\circ} \mathrm{C}$ ) and the second corresponds to the distal temperature (i.e., $49^{\circ} \mathrm{C}$ ). During divided and directed attentional conditions, the underlined temperature corresponds to the site from which the rating was obtained.

Psychophysical assessment and training. After each stimulus, pain intensity and pain unpleasantness were rated with mechanical visual analog scales (VASs). These $15 \mathrm{~cm}$ sliding scales were anchored with the words "no pain sensation", "the most intense pain imaginable" and "not unpleasant at all", "the most unpleasant imaginable," respectively. After subjects slid the scale to the appropriate level that corresponded to their actual pain perception, the ratings were quantified by a labeled numeric index (0-10 range) on the back of the scale that was out of the subjects' view. Subjects were asked about their thermal sensation from a probe at $35^{\circ} \mathrm{C}$ and described it as a neutral skin temperature with no reports of cold/warm/pain from the area (VAS, 0).

Two series of training stimuli were used before starting the experiment. In the first training series, a single probe delivering different temperatures (from 35 to $49^{\circ} \mathrm{C}$ ) was used to give subjects experience rating pain intensity and pain unpleasantness. In the second training series, pairs of thermal stimuli (combinations of 35 and $49^{\circ} \mathrm{C}$ ) separated by 10 $\mathrm{cm}$ were delivered to the medial surface of the leg. This second training series allowed subjects to gain experience in providing ratings for two stimuli delivered simultaneously while using different attentional strategies. Subjects reported that they were able to perform the directed and divided tasks after a few trials without any problems. The relative ease with which subjects were able to learn the tasks suggests that the difficulty or stress associated with making these more complex ratings contributed minimally to alterations in spatial integration.

Attentional tasks. Attention was manipulated by using three different pain rating tasks. First, subjects were required to give one overall rating of two simultaneous thermal stimuli. Overall ratings have been widely used to assess spatial summation of pain and require the integration of nociceptive information across large body areas (Price et al., 1989; Nielsen and Arendt-Nielsen, 1997). Second, subjects were instructed to divide their attention by separately rating both stimuli and giving two ratings, one from each stimulus. This task requires subjects to minimize nociceptive integration to better evaluate pain from each locus. When attention was divided by requiring subjects to provide two different ratings, indirect evidence suggests that pain may be inhibited (Quevedo and Coghill, 2007). Third, subjects were required to direct their attention to one of the two loci and provide only one rating of pain from the specified locus. Importantly they were instructed to disregard information from the other locus. This condition serves as a control for nonspecific effects of attention. To control for multisensory interactions, subjects were required to focus their gaze on the midpoint between the probes during the time that paired stimuli were delivered.

Modulation of spatial interactions between multiple noxious stimuli by different attentional tasks. To test the hypothesis that the divided attention task is able to reduce spatial summation of pain, subjects received pairs of $49 / 49^{\circ} \mathrm{C}$ stimuli applied unilaterally to the lower leg. To minimize sensitization, testing was distributed across both legs. Repeated measures analyses of variance were used to compare pain ratings when subjects performed three different attentional tasks: divided attention, directed attention, and overall ratings. The following specific post hoc comparisons were made for both proximal and distal sites: (1) to investigate the influence of division of attention on spatial summation of pain, ratings during divided attention were compared with overall ratings. (2) To investigate whether disruption of spatial summation caused by the divided attention task is attributable to general attentional modulation or results from a specific spatial attentional set, pain ratings during divided attention were compared with those during directed attention. (3) To evaluate the possible inhibition during divided attention tasks, pain ratings during divided attention were compared with ratings from single $49^{\circ} \mathrm{C}$ stimuli.

To determine whether disruption of spatial summation of pain during the divided attention task was accompanied by an attentionally mediated inhibition of pain rather than a tactile inhibitory effect resulting from the presence of a second probe, a $49^{\circ} \mathrm{C}$ stimulus was coupled with a neutral thermal probe during two different conditions. In one condition the neutral thermal probe was visibly disconnected from the control device and had a zero percent probability of being activated $\left(49^{\circ} \mathrm{C} / \mathrm{off}\right)$. In the other condition, the neutral thermal probe was set at $35^{\circ} \mathrm{C}$ (skin temperature), but subjects were aware that the probe could be activated (50\% probability) at a noxious temperature. Pain ratings from the $49^{\circ} \mathrm{C} / \mathrm{off}$ were compared with pain ratings from $49^{\circ} \mathrm{C}$ coupled to a probe with high probability of being activated $\left(50 \% 35^{\circ} \mathrm{C} / 50 \% 49^{\circ} \mathrm{C}\right)$. In addition, pain ratings from the $49^{\circ} \mathrm{C} / \mathrm{off}$ condition were also compared with those from single $49^{\circ} \mathrm{C}$ stimuli to determine whether inhibition was evoked during simultaneous noxious and tactile stimulation.

\section{Results}

The two assessed aspects of pain (intensity and unpleasantness) were highly similar; thus, for clarity, analyses focused only on pain intensity. Perceived pain intensity was significantly modulated according to the attentional condition $\left(F_{(3,12)}=12.46 ; p<\right.$ $0.0005)$. During pairs of $49 / 49^{\circ} \mathrm{C}$ stimuli, divided attention abolished spatial summation of pain. Separate ratings of pain intensity at distal $\left(F_{(1,14)}=52.80 ; p<0.0001\right)($ Fig. $2 A)$ and proximal $\left(F_{(1,14)}=23.63 ; p<0.0001\right)$ (Fig. $2 B$ ) sites were both significantly lower than overall ratings of pairs of $49 / 49^{\circ} \mathrm{C}$ stimuli. These reduced ratings were not induced by general attentional effects because pain ratings during the directed attention condition remained significantly greater than those during the divided 
A. Distal

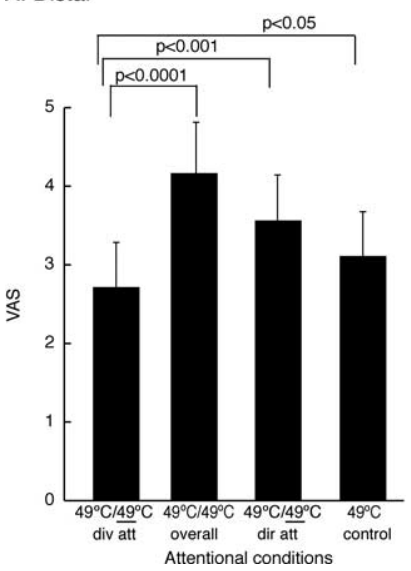

B. Proximal

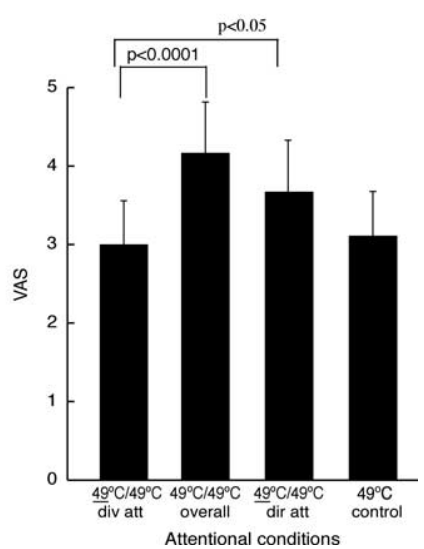

Figure 2. Attention modulates spatial integration of information from two noxious stimuli (mean \pm SEM). $\boldsymbol{A}, \boldsymbol{B}$, During divided attention (div att; $49 / 49^{\circ} \mathrm{C}$ and $49 / 49^{\circ} \mathrm{C}$ ) spatial summation of pain $\left(49 / 49^{\circ} \mathrm{C}\right.$ overall) was abolished at distal $\left(49 / 49^{\circ} \mathrm{C}\right.$ div att; $\left.\boldsymbol{A}\right)$ and proximal sites $\left(49 / 49^{\circ} \mathrm{C}\right.$ div att; $\left.\boldsymbol{B}\right)$. This was associated with inhibition when compared with a single $49^{\circ} \mathrm{C}(49$ control) at distal stimuli $(\boldsymbol{A})$ but not at proximal sites $(\boldsymbol{B})$. The modulation of pain was not attributable to nonspecific attentional effects because during the directed attention (dir att; $49 / 49^{\circ} \mathrm{C}$ and $\left.49 / 49^{\circ} \mathrm{C}\right)$ pain ratings were greater than during divided attention at distal $\left(49 / 49^{\circ} \mathrm{C}\right.$ $\operatorname{div}$ att; $\boldsymbol{A})$ and proximal $\left(49 / 49^{\circ} \mathrm{C} \operatorname{div}\right.$ att; $\left.\boldsymbol{B}\right)$ sites.
A. Distal

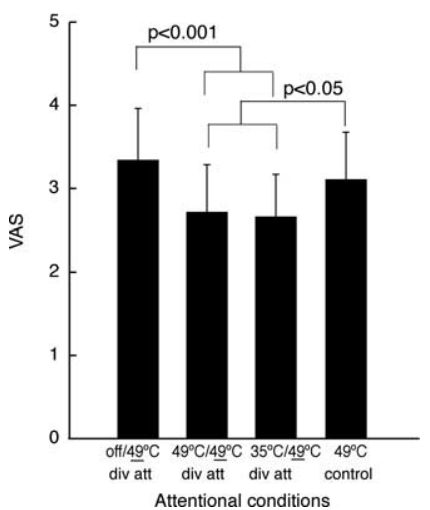

B. Proximal

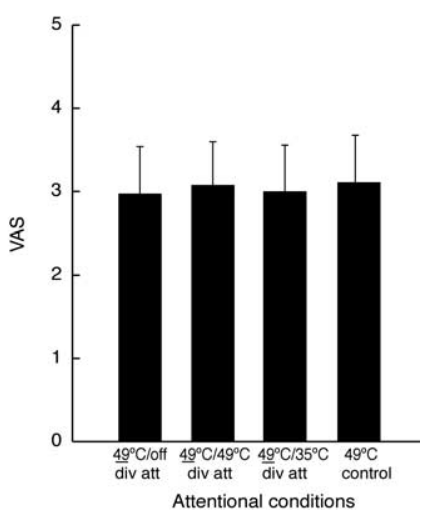

Figure 3. Division of attention produces inhibition of pain (mean \pm SEM). $\boldsymbol{A}$, During the stimulus conditions where proximal probes had a high probability $(50 \%)$ of being activated $\left(35 / 49^{\circ} \mathrm{C}\right.$ and $\left.49 / 49^{\circ} \mathrm{C}\right)$, distal pain ratings were significantly reduced relative to single stimuli and to conditions where the proximal probe had a low probability $(0 \%)$ of being activated (off $/ 49^{\circ} \mathrm{C}$ ). $\boldsymbol{B}$, Such reduction in pain ratings was not observed at proximal sites.

attention condition at both distal $\left(F_{(1,14)}=13.03 ; p<0.001\right)$ (Fig. $2 A)$ and proximal $\left(F_{(1,14)}=7.18 ; p<0.05\right)$ (Fig. $2 B$ ) sites.

The abolition of spatial summation of pain during divided attention appears to involve a partial inhibition of pain. During the divided attention condition, pain from the distal site during paired $49 / 49^{\circ} \mathrm{C}$ stimulation was significantly lower than pain from a single $49^{\circ} \mathrm{C}$ stimulus $\left(F_{(1,14)}=4.96 ; p<0.05\right)($ Fig. $2 A)$. However, there was no inhibitory effect of divided attention at the proximal stimulus site $\left(F_{(1,14)}=0.34 ; p<0.5\right)$ (Fig. $\left.2 B\right)$.

The attentional set appears to be critical for inhibition of pain and inhibition of spatial summation of pain during the divided attention condition. During the divided attention condition, ratings of distal $49^{\circ} \mathrm{C}$ stimuli were significantly modulated by the attentional demands of the proximal stimulus condition $\left(F_{(2,13)}\right.$ $=4.71 ; p<0.029)$ (Fig. 3A). When the proximal stimuli had a high probability of being activated $\left(35 / 49^{\circ} \mathrm{C}\right.$ and $\left.49 / 49^{\circ} \mathrm{C}\right)$, rat- ings of distal $49^{\circ} \mathrm{C}$ stimuli were significantly reduced relative to those of single $49^{\circ} \mathrm{C}$ control stimuli $\left(F_{(1,14)}=5.82 ; p<0.03\right)$, respectively (Fig. $3 A$ ).

To further determine whether this inhibition is attributable specifically to the attentional demands of the divided rating task, subjects rated pain from a distal $49^{\circ} \mathrm{C}$ stimulus when the proximal probe was visibly disconnected $\left(\mathrm{off} / 49^{\circ} \mathrm{C}\right)$ and had a zero percent probability of being activated. When the proximal probe had a low probability of activation $\left(\mathrm{off} / 49^{\circ} \mathrm{C}\right)$, the distal ratings were significantly higher than in conditions where the proximal probe had a high probability of activation $\left(49 / 49^{\circ} \mathrm{C}\right.$ or $\left.35 / 49^{\circ} \mathrm{C}\right)$ $\left(F_{(1,14)}=9.10 ; p<0.001\right)$ (Fig. $3 A$ ). These data indicate that the inhibition found during the divided attention condition is not evoked by tactile stimulation from an additional probe on the skin, but is caused by the division of attention between the two different stimulated areas.

During the divided attention condition, spatial summation of pain was abolished at distal (Fig. 2A) and proximal sites (Fig. $2 B$ ). However, unlike distal sites where the reduction in spatial summation of pain was accompanied by inhibition of pain (Fig. $3 \mathrm{~A}$ ), ratings of proximal $49^{\circ} \mathrm{C}$ stimuli were not modulated by the attentional demands of the distal stimulus condition $\left(F_{(1,14)}=\right.$ $0.45 ; p<0.5$ ) (Fig. $3 B$ ). The divided attention condition did not produce inhibition of proximal stimuli during $49 / 49^{\circ} \mathrm{C}$ or 49 / $35^{\circ} \mathrm{C}$ when compared with single $49^{\circ} \mathrm{C}$ control stimuli $\left(F_{(1,14)}=\right.$ $0.22 ; p<0.6)$ and $49^{\circ} \mathrm{C} /$ off conditions $\left(F_{(1,14)}=0.43 ; p<0.5\right)$, respectively (Fig. $3 B$ ).

\section{Discussion}

The function of our perceptual system is not only to detect, but also to modulate incoming information (Koyama et al., 2005) to facilitate the creation of sensation from internal representations of our sensory environment. Attention, in this context, would allow us to integrate or isolate peripheral stimuli and organize the nervous system response to optimize our performance to solve a given problem. Across different modalities such as vision (Salinas and Abbott, 1997), audition (King et al., 2007), and somatosensation (Faggin et al., 1997), one way to better adapt the nervous system to various situations is by dynamically modulating how information is processed. Central plasticity of sensory maps can be implemented by bottom-up (Pleger et al., 2001) or top-down mechanisms (Braun et al., 2002) that are activated in contextdependent fashions according to the circumstances of the environment or cognitive demands. Rapid and reversible plasticity in the somatosensory system has been reported (Stavrinou et al., 2006) in the dorsal horn (Hayes et al., 1981), dorsal column nuclei (Pettit and Schwark, 1993), brainstem (Faggin et al., 1997), thalamus (Faggin et al., 1997), and cortex (Faggin et al., 1997). This dynamic modulation can explain the differential integration/segregation between the two noxious stimuli in the present study.

Spatial summation of pain during overall ratings has been repeatedly identified (Price et al., 1989; Greenspan et al., 1997) and is thought to reflect static spatial integration resulting from the intrinsic RF proprieties of nociceptive neurons. Importantly, the division of attention between two stimuli abolished spatial summation and may reflect the initiation of inhibitory processes (Oshiro et al., 2007; Quevedo and Coghill, 2007). Reduction of pain during multifocal noxious stimulation can result when one noxious stimulus inhibits another (Le Bars et al., 1979). However, when a neutral temperature probe that had a $50 \%$ probability of being activated was coupled to a noxious stimulus, similar inhibition of pain was obtained. This indicates that the inhibition 
A. No attention required
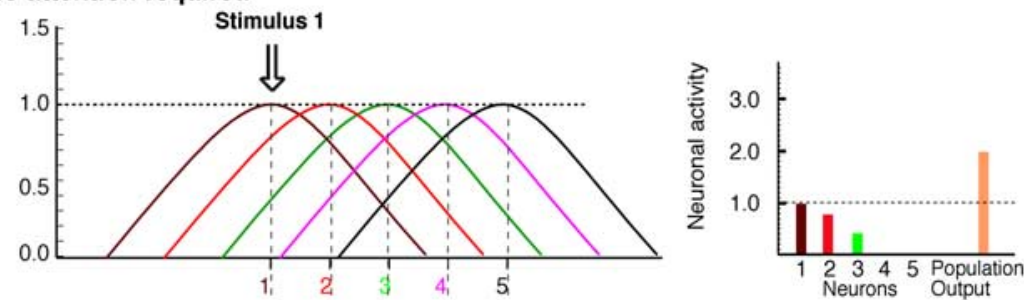

B. Directed attention
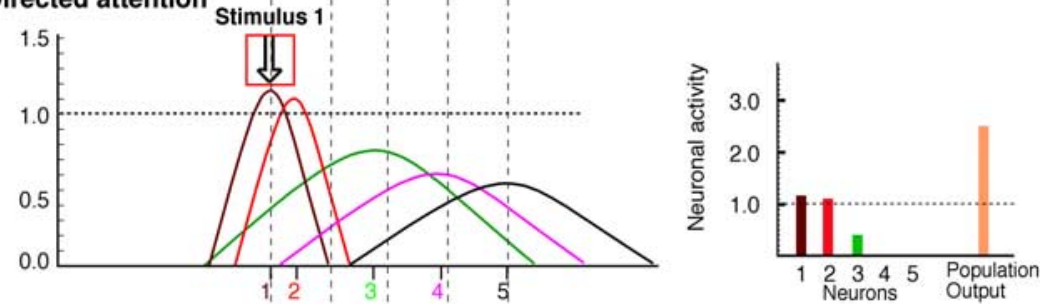

竞

C. Directed attention

竞
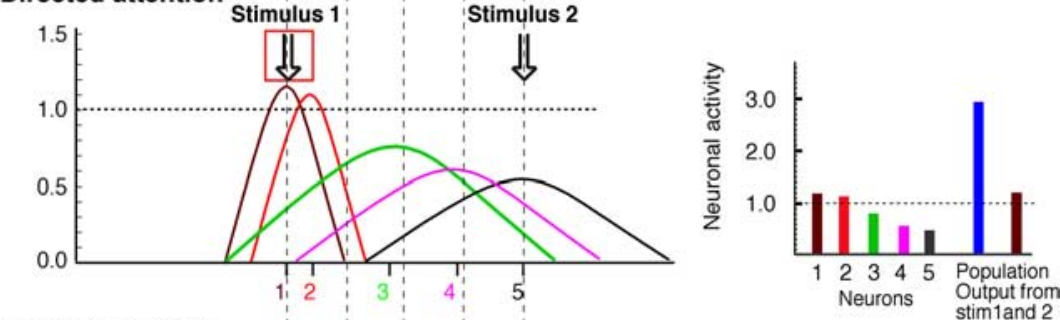

D. Divided attention
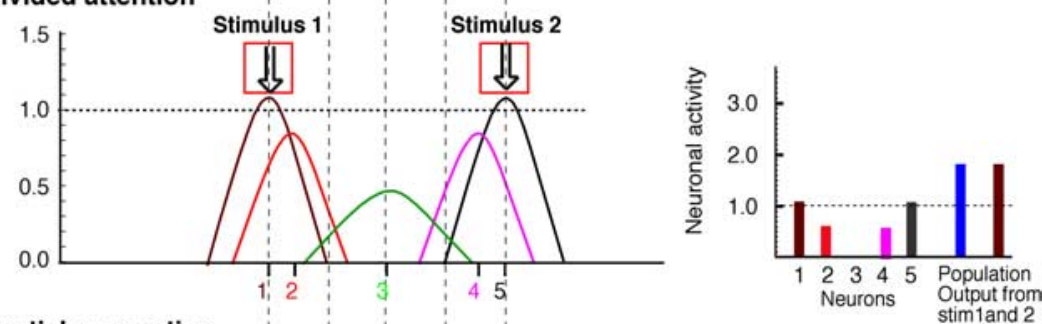

E. Spatial summation
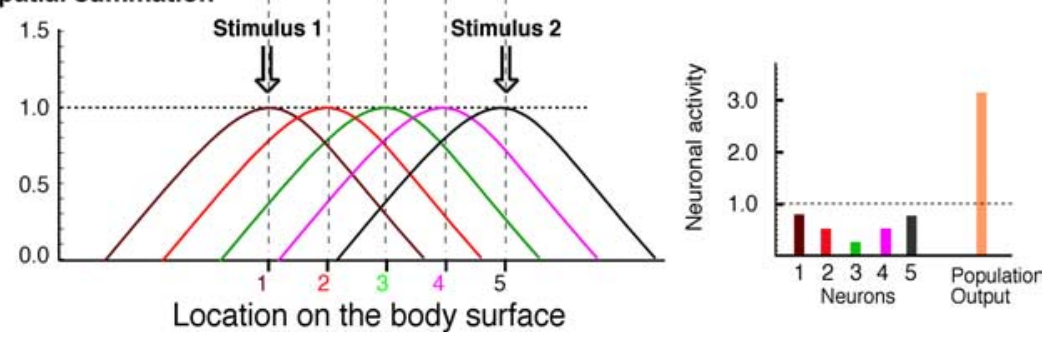

Figure 4. Conceptualization of attentional effects on RF organization and spatial integration of nociceptive information. Left, Spatial distribution of RF of nociceptive neurons innervating the body surface. The $x$-axis represents the location of the receptive field on the body surface whereas the $y$-axis represents the sensitivity of that neuron at a given spatial location. Each neuron is numbered in the center of its RF. Vertical dashed lines originate from the center of the RFs of neurons in $A$ to demonstrate RF shifts in $\boldsymbol{B}-\boldsymbol{E}$. Right, Magnitude of the activation of each individual neuron and the total neuronal population output used for the subjective evaluation of pain. A value of 1 represents the evoked responses from stimulation in the center of the RF (i.e., neuron 1; A). Population outputs were derived from the sum of the neural output of all neurons activated by a given stimulus. If a neuron was activated by both stimuli, its total activity is added to both population outputs. The red square symbolizes the site where subjects were required to pay attention. $A$, Each individual neuron is represented with a different color. During a single noxious stimulus without any spatial attentional requirement, different activation is found in neurons depending on their RF location in relation to the stimulus. The hypothetical output from the population is $\sim 2.0$. $\boldsymbol{B}$. When subjects are required to direct their attention to a single noxious stimulus ( 49 control condition), there is an enhancement of sensitivity inside the target area and a focusing of the RFs that have their centers close to the stimulus. Also the RFs of neurons adjacent to the stimuli $(2,3$, and 4$)$ are shifted to the attended area. The neurons far away from the focus of attention (5) have their activity diminished to better contrast between attended and nonattended areas. This pattern of activity is consistent with that predicted by the spotlight/multiplicative enhancement effect (Compte and Wang, 2006). The population output is 2.5. C, Two noxious thermal stimuli are applied simultaneously and subjects are required to direct their attention to only stimulus $1\left(49^{\circ} \mathrm{C} / 49^{\circ} \mathrm{C}\right.$ directed attention). As in $\boldsymbol{B}$, there is enhanced sensitivity inside the target area and diminished sensitivity to the nonattended stimulus. However, some neurons (3) are activated by both stimuli and integrate them. This interaction of neuronal activity can account for the slight increase of pain during the during paired noxious stimulation was not caused by a "pain-inhibiting pain" phenomenon. One alternative possibility is that the presence of a second probe on the skin produces inhibition via $\mathrm{A} \beta$ fiber input. However, when subjects were aware that one probe had a $0 \%$ probability of being activated, pain ratings did not fall during the divided attention condition. Thus, tactile stimulation did not produce inhibition. Given that inhibition and/or abolition of spatial summation was observed when the probes had a high probability of being activated, these reductions in pain may be attributed to the attentional task that the subjects were performing.

Alterations in spatial summation of pain during divided attention could be attributed to a general, nonspecific effect of attention that could be driven by the cognitive difficulty of rating two stimuli simultaneously, general arousal attributable to the difficulty of the rating task, and other similar factors. To determine the specificity of the attentional effect, a second attentional task (directed attention) was used. Pain during the divided attention task was significantly reduced in comparison with pain during the directed attention task. Thus, the modulation of spatial summation is not caused by general attentional effects, but varies according to the spatial focus of the specific attentional condition.

During the divided attentional condition, spatial summation was abolished and inhibitory effects were found. However, when compared with the control condition $\left(49^{\circ} \mathrm{C}\right.$ alone $)$, pain ratings decreased only at distal stimulus sites (Fig. 3A). Distally directed inhibition has been reported previously (Quevedo and Coghill, 2007) and may be important for optimizing withdrawal responses (Morgan et al., 1994).

directed attention condition and produces an increase in the population output for stimulus $1(\sim 3.0)$. D. Two noxious thermal stimuli are applied simultaneously and subjects are asked to divide their attention between the two stimuli (49/ $49^{\circ} \mathrm{C}$ divided attention). This task requires segregation of information from the two stimuli, so increased surround inhibition is used to create a silent zone in the intermediate area. Also to improve spatial resolution, RF sizes are reduced to better distinguish information from each of the two stimuli. Accordingly, spatial summation of pain is not allowed to occur and inhibition is produced ( $\boldsymbol{B}$ v $\boldsymbol{D}$ ). The population output for each stimulus is 1.8. $\boldsymbol{E}$, Two noxious thermal stimuli are applied simultaneously and subjects are required to integrate pain experience from both stimuli $\left(49 / 49^{\circ} \mathrm{C}\right.$, no spatial attention required, overall ratings). There is no spatial focusing of RF (shrinking around the stimuli), and spatial summation of pain is produced. Accordingly, the population output is 3.2. 


\section{Potential mechanism of spatial tuning}

Noxious stimulus intensity can be represented by the discharge frequency of single neurons, as well as by the total population output of activated neurons (Coghill et al., 1993). Computational models indicate that attentional focus can tune the population activity of neurons responding to a particular stimulus by modulating the size and/or position of their RFs to optimize the response to input from a particular area or stimulus feature (Salinas and Abbott, 1997; Salinas and Thier, 2000; Compte and Wang, 2006).

During the divided attention condition, the minimization of spatial interactions between stimuli as well as the inhibitory effects may have been accomplished by (1) shrinking excitatory RFs, (2) increasing the efficacy of the surround inhibition, and/or (3) shifting the RFs. Such spatial tuning would yield a population response with two distinct foci of excitatory activity with a silent area between them (Fig. 4D). In addition, the total population response to the two stimuli would be decreased and would provide inhibition and/or abolition of spatial summation of pain.

During overall ratings, pain from both stimuli needs to be evaluated as a single entity. Thus, spatial convergence between stimuli has to be maximized. This can be accomplished by (1) increasing the size or efficiency of excitatory RFs in both areas and/or (2) decreasing of the efficiency of surround inhibition. In both cases, neuronal population output increases and could explain the perception of greater pain intensity as compared with the divided attentional condition (Fig. $4 E$ ).

During the directed attention condition, the system has to optimally extract information from a single area by (1) expanding or increasing efficiency of the excitatory RF in this particular area and/or (2) shifting neighboring RFs to participate in the stimulus coding. For example, some neurons that are recruited to process the attended stimulus might also be activated by the unattended stimulus, thereby yielding increased pain relative to single control stimuli (Fig. 4C).

The short-term changes in the sensory representation can be attributed to "pseudoplasticity" where morphological modifications are not required. RFs can be reshaped by inhibitory interneurons (Foeller et al., 2005) and/or by recurrent excitatory connections (Finnerty et al., 1999). For example, local administration of GABA antagonists can change the size of the RFs of dorsal horn (Yokota and Nishikawa, 1982) and SI (Tremere et al., 2001) neurons. RF tuning can be modulated by CNS circuits that convey information about training and/or attentional requirements (Gilbert, 1998). This top-down modulation can select higher-order representations of lower-level sensory features that better fit in a single event/task (polymaps) (Swindale et al., 2000), using short-term neuroplastic mechanisms activated by attention (Braun et al., 2002).

\section{Cortical/subcortical activity and attention}

In the dorsal horn, descending pathways may modulate incoming nociceptive information at presynaptic levels (primary afferent), second order neurons, intrinsic interneurons, or at terminals of other descending pathways (Millan, 2002). This richly interconnected environment can provide numerous substrates for top-down dynamic modulation of the RF properties of nociceptive neurons. For example, visual attentional cues signaling impending stimuli produce activity in spinothalamic neurons during discrimination tasks (Duncan et al., 1987). Also, a second order neuron that is not activated by a contralateral noxious stimulus starts to respond to such a stimulus when attention is directed to the contralateral site (Hayes et al., 1981). Such spa- tially focused dynamic changes can also be produced by other top-down effects (Price et al., 1989; Porro et al., 2003). For example, endogenous opioid-mediated placebo analgesia can be highly topographically organized (Benedetti et al., 1999).

In humans, dorsolateral prefrontal cortex (DLPFC), orbitofrontal cortex, and anterior cingulate cortex (ACC) are involved in both attention (Bantick et al., 2002; Luks et al., 2007) and pain modulation (Bantick et al., 2002). Activation of these areas is correlated with decreased pain ratings during attention demanding tasks (Bantick et al., 2002; Valet et al., 2004). Across different species, numerous prefrontal areas (Hardy and Leichnetz, 1981; Floyd et al., 2000) and ACC (Floyd et al., 2000) have been found to project to the periaqueductal gray (PAG). In humans, the PAG is activated during cognitive and attentional tasks and, together with other brainstem regions (Heinricher et al., 1997), is able to modulate nociceptive processing (Tracey et al., 2002). Diffusion tensor imaging data indicates that the PAG connects to DLPFC via thalamus (Hadjipavlou et al., 2006) and imaging studies have confirmed physiological interactions between ACC and PAG (Valet et al., 2004). Moreover, direct anatomical connections from ACC to the spinal cord have been found (Dum and Strick, 1996). Together, these findings suggest that cingulofrontal regions may exert top-down cognitive and attentional control of spinal pain modulation (Valet et al., 2004).

\section{Corticocortical modulation}

Part of the sensory modulation found in the present investigation may also be attributed to corticocortical interactions. For example, training and learning can produce changes in the functional topography of SI (Elbert et al., 1995) and attention may also modulate SI activity (Noppeney et al., 1999). During cognitive tasks involving prefrontal areas, topographic representation shifts in SI may promote a greater segregation between two body regions (Schaefer et al., 2005). This short-term plasticity may be regulated by a prefrontal-cortical sensory gating system that uses facilitation and suppression to perform dynamic modulation of sensory processing (Staines et al., 2002).

\section{Final considerations}

Attention can alter inputs at upstream sites by selecting/filtering the crucial information to be processed downstream. Brain areas involved in attention can differentially preset the nervous system to perform a given spatial attentional task. When subjects direct or divide their attention, they optimize the integration/segregation of nociceptive information across responsive neuronal populations. The identification of this dynamic spatial tuning of nociceptive processes represents a new conceptual insight into the functional significance of endogenous pain inhibitory and facilitatory mechanisms.

\section{References}

Ahveninen J, Jaaskelainen IP, Raij T, Bonmassar G, Devore S, Hamalainen M, Levanen S, Lin FH, Sams M, Shinn-Cunningham BG, Witzel T, Belliveau JW (2006) Task-modulated "what" and "where" pathways in human auditory cortex. Proc Natl Acad Sci USA 103:14608-14613.

Andersen OK, Jensen LM, Brennum J, Arendt-Nielsen L (1994) Evidence for central summation of $\mathrm{C}$ and A delta nociceptive activity in man. Pain 59:273-280.

Bantick SJ, Wise RG, Ploghaus A, Clare S, Smith SM, Tracey I (2002) Imaging how attention modulates pain in humans using functional MRI. Brain 125:310-319.

Benedetti F, Arduino C, Amanzio M (1999) Somatotopic activation of opioid systems by target-directed expectations of analgesia. J Neurosci 19:3639-3648.

Braun C, Haug M, Wiech K, Birbaumer N, Elbert T, Roberts LE (2002) 
Functional organization of primary somatosensory cortex depends on the focus of attention. Neuroimage 17:1451-1458.

Buell TN, Hafter ER (1991) Combination of binaural information across frequency bands. J Acoust Soc Am 90:1894-1900.

Coghill RC, Mayer DJ, Price DD (1993) The roles of spatial recruitment and discharge frequency in spinal cord coding of pain: a combined electrophysiological and imaging investigation. Pain 53:295-309.

Compte A, Wang XJ (2006) Tuning curve shift by attention modulation in cortical neurons: a computational study of its mechanisms. Cereb Cortex 16:761-778.

Dum RP, Strick PL (1996) Spinal cord terminations of the medial wall motor areas in macaque monkeys. J Neurosci 16:6513-6525.

Duncan GH, Bushnell MC, Bates R, Dubner R (1987) Task-related responses of monkey medullary dorsal horn neurons. J Neurophysiol 57:289-310.

Elbert T, Junghofer M, Scholz B, Schneider S (1995) The separation of overlapping neuromagnetic sources in first and second somatosensory cortices. Brain Topogr 7:275-282.

Faggin BM, Nguyen KT, Nicolelis MA (1997) Immediate and simultaneous sensory reorganization at cortical and subcortical levels of the somatosensory system. Proc Natl Acad Sci USA 94:9428 -9433.

Finnerty GT, Roberts LS, Connors BW (1999) Sensory experience modifies the short-term dynamics of neocortical synapses. Nature 400:367-371.

Floyd NS, Price JL, Ferry AT, Keay KA, Bandler R (2000) Orbitomedial prefrontal cortical projections to distinct longitudinal columns of the periaqueductal gray in the rat. J Comp Neurol 422:556-578.

Foeller E, Celikel T, Feldman DE (2005) Inhibitory sharpening of receptive fields contributes to whisker map plasticity in rat somatosensory cortex. J Neurophysiol 94:4387-4400.

Gilbert CD (1998) Adult cortical dynamics. Physiol Rev 78:467-485.

Greenspan JD, Thomadaki M, McGillis SL (1997) Spatial summation of perceived pressure, sharpness and mechanically evoked cutaneous pain. Somatosens Mot Res 14:107-112.

Hadjipavlou G, Dunckley P, Behrens TE, Tracey I (2006) Determining anatomical connectivities between cortical and brainstem pain processing regions in humans: a diffusion tensor imaging study in healthy controls. Pain 123:169-178.

Hardy SG, Leichnetz GR (1981) Cortical projections to the periaqueductal gray in the monkey: a retrograde and orthograde horseradish peroxidase study. Neurosci Lett 22:97-101.

Harutiunian-Kozak BA, Sharanbekian AB, Kazarian AL, Grigorian GG, Kozak JA, Sarkisyan GS, Khachvankian DK (2006) Spatial summation processes in the receptive fields of visually driven neurons of the cat's cortical area 21a. Arch Ital Biol 144:127-144.

Hayes RL, Dubner R, Hoffman DS (1981) Neuronal activity in medullary dorsal horn of awake monkeys trained in a thermal discrimination task. II. Behavioral modulation of responses to thermal and mechanical stimuli. J Neurophysiol 46:428-443.

Heinricher MM, McGaraughty S, Grandy DK (1997) Circuitry underlying antiopioid actions of orphanin FQ in the rostral ventromedial medulla. J Neurophysiol 78:3351-3358.

Hilz MJ, Stemper B, Axelrod FB, Kolodny EH, Neundorfer B (1999) Quantitative thermal perception testing in adults. J Clin Neurophysiol 16:462-471.

King AJ, Bajo VM, Bizley JK, Campbell RA, Nodal FR, Schulz AL, Schnupp JW (2007) Physiological and behavioral studies of spatial coding in the auditory cortex. Hear Res 229:106-115.

Koyama T, McHaffie JG, Laurienti PJ, Coghill RC (2005) The subjective experience of pain: where expectations become reality. Proc Natl Acad Sci USA 102:12950-12955.

Le Bars D, Dickenson AH, Besson JM (1979) Diffuse noxious inhibitory controls (DNIC). I. Effects on dorsal horn convergent neurones in the rat. Pain 6:283-304.

Luks TL, Simpson GV, Dale CL, Hough MG (2007) Preparatory allocation of attention and adjustments in conflict processing. Neuroimage 35:949-958.
McAdams CJ, Maunsell JH (1999) Effects of attention on orientationtuning functions of single neurons in macaque cortical area V4. J Neurosci 19:431-441.

Millan MJ (2002) Descending control of pain. Prog Neurobiol 66:355-474.

Morgan MM, Heinricher MM, Fields HL (1994) Inhibition and facilitation of different nocifensor reflexes by spatially remote noxious stimuli. J Neurophysiol 72:1152-1160.

Nielsen J, Arendt-Nielsen L (1997) Spatial summation of heat induced pain within and between dermatomes. Somatosens Mot Res 14:119-125.

Noppeney U, Waberski TD, Gobbele R, Buchner H (1999) Spatial attention modulates the cortical somatosensory representation of the digits in humans. Neuroreport 10:3137-3141.

Oshiro Y, Quevedo AS, McHaffie JG, Kraft RA, Coghill RC (2007) Brain mechanisms supporting spatial memory and spatial discrimination of pain. J Neurosci 27:3388-3394.

Pettit MJ, Schwark HD (1993) Receptive field reorganization in dorsal column nuclei during temporary denervation. Science 262:2054-2056.

Pleger B, Dinse HR, Ragert P, Schwenkreis P, Malin JP, Tegenthoff M (2001) Shifts in cortical representations predict human discrimination improvement. Proc Natl Acad Sci USA 98:12255-12260.

Porro CA, Cavazzuti M, Lui F, Giuliani D, Pellegrini M, Baraldi P (2003) Independent time courses of supraspinal nociceptive activity and spinally mediated behavior during tonic pain. Pain 104:291-301.

Price DD, Dubner R (1977) Neurons that subserve the sensorydiscriminative aspects of pain. Pain 3:307-338.

Price DD, McHaffie JG, Larson MA (1989) Spatial summation of heatinduced pain: influence of stimulus area and spatial separation of stimuli on perceived pain sensation intensity and unpleasantness. J Neurophysiol 62:1270-1279.

Quevedo AS, Coghill RC (2007) An illusion of proximal radiation of pain due to distally directed inhibition. J Pain 8:280-286.

Quraishi S, Heider B, Siegel RM (2006) Attentional modulation of receptive field structure in area $7 \mathrm{a}$ of the behaving monkey. Cereb Cortex 17:1841-1857.

Salinas E, Abbott LF (1997) Invariant visual responses from attentional gain fields. J Neurophysiol 77:3267-3272.

Salinas E, Thier P (2000) Gain modulation: a major computational principle of the central nervous system. Neuron 27:15-21.

Schaefer M, Heinze HJ, Rotte M (2005) Task-relevant modulation of primary somatosensory cortex suggests a prefrontal-cortical sensory gating system. Neuroimage 27:130-135.

Staines WR, Graham SJ, Black SE, McIlroy WE (2002) Task-relevant modulation of contralateral and ipsilateral primary somatosensory cortex and the role of a prefrontal-cortical sensory gating system. Neuroimage 15:190-199.

Stavrinou ML, Della Penna S, Pizzella V, Torquati K, Cianflone F, Franciotti R, Bezerianos A, Romani GL, Rossini PM (2006) Temporal dynamics of plastic changes in human primary somatosensory cortex after finger webbing. Cereb Cortex 17:2134-2142.

Swindale NV, Shoham D, Grinvald A, Bonhoeffer T, Hubener M (2000) Visual cortex maps are optimized for uniform coverage. Nat Neurosci 3:822-826.

Tracey I, Ploghaus A, Gati JS, Clare S, Smith S, Menon RS, Matthews PM (2002) Imaging attentional modulation of pain in the periaqueductal gray in humans. J Neurosci 22:2748-2752.

Tremere L, Hicks TP, Rasmusson DD (2001) Expansion of receptive fields in raccoon somatosensory cortex in vivo by GABA(A) receptor antagonism: implications for cortical reorganization. Exp Brain Res 136:447-455.

Valet M, Sprenger T, Boecker H, Willoch F, Rummeny E, Conrad B, Erhard P, Tolle TR (2004) Distraction modulates connectivity of the cingulofrontal cortex and the midbrain during pain-an fMRI analysis. Pain 109:399-408.

Yokota T, Nishikawa N (1982) Effects of picrotoxin upon response characteristics of wide dynamic range neurons in the spinal cord of cat and monkey. Neurosci Lett 28:259-263. 